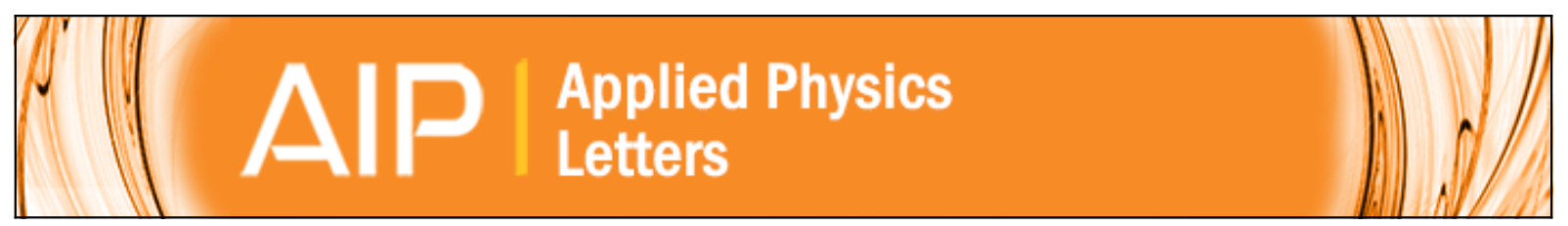

\title{
Functional integrity of flexible n-channel metal-oxide-semiconductor field-effect transistors on a reversibly bistable platform
}

Nasir Alfaraj, Aftab M. Hussain, Galo A. Torres Sevilla, Mohamed T. Ghoneim, Jhonathan P. Rojas,

Abdulrahman B. Aljedaani, and Muhammad M. Hussain

Citation: Applied Physics Letters 107, 174101 (2015); doi: 10.1063/1.4934355

View online: http://dx.doi.org/10.1063/1.4934355

View Table of Contents: http://scitation.aip.org/content/aip/journal/apl/107/17?ver=pdfcov

Published by the AIP Publishing

\section{Articles you may be interested in}

Hot carrier effect on gate-induced drain leakage current in high-k/metal gate n-channel metal-oxidesemiconductor field-effect transistors

Appl. Phys. Lett. 99, 012106 (2011); 10.1063/1.3608241

Strain induced changes in the gate leakage current of $n$-channel metal-oxide-semiconductor field-effect transistors

J. Appl. Phys. 110, 014511 (2011); 10.1063/1.3603023

The proximity of the strain induced effect to improve the electron mobility in a silicon-carbon source-drain structure of $\mathrm{n}$-channel metal-oxide-semiconductor field-effect transistors

Appl. Phys. Lett. 96, 093501 (2010); 10.1063/1.3340926

Enhancement-mode InP $\mathrm{n}$-channel metal-oxide-semiconductor field-effect transistors with atomic-layerdeposited Al 203 dielectrics

Appl. Phys. Lett. 91, 022108 (2007); 10.1063/1.2756106

Study of strain relaxation in Si/SiGe metal-oxide-semiconductor field-effect transistors

J. Appl. Phys. 97, 114504 (2005); 10.1063/1.1922582

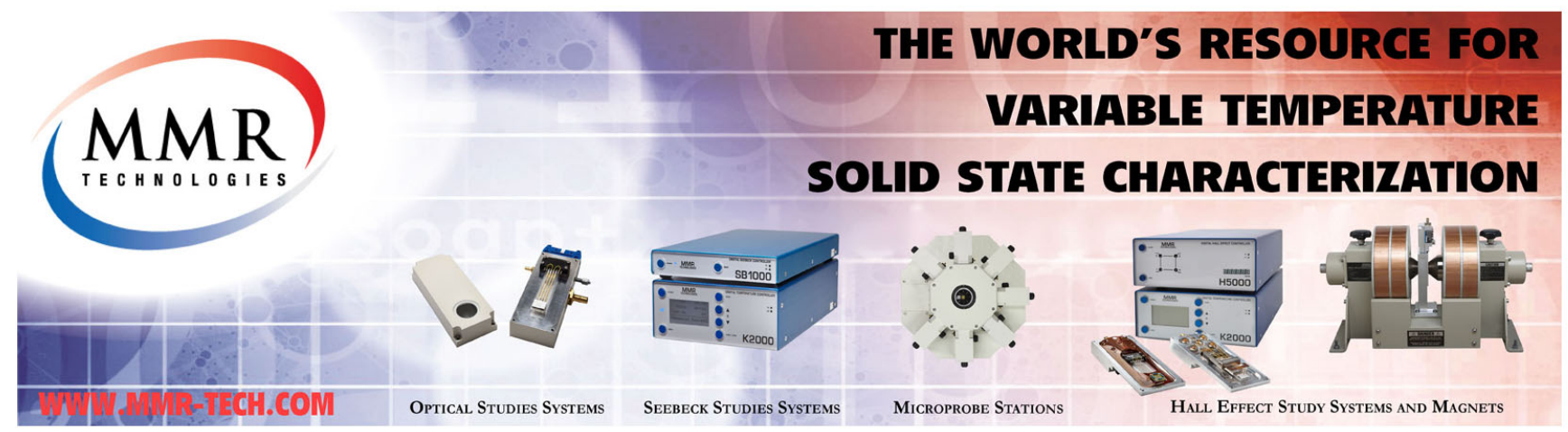




\title{
Functional integrity of flexible $n$-channel metal-oxide-semiconductor field-effect transistors on a reversibly bistable platform
}

\author{
Nasir Alfaraj, ${ }^{1}$ Aftab M. Hussain, ${ }^{1}$ Galo A. Torres Sevilla, ${ }^{1}$ Mohamed T. Ghoneim, ${ }^{1}$ \\ Jhonathan P. Rojas, ${ }^{1}$ Abdulrahman B. Aljedaani, ${ }^{2}$ and Muhammad M. Hussain ${ }^{1, a)}$ \\ ${ }^{1}$ Integrated Nanotechnology Laboratory, Computer, Electrical and Mathematical Sciences and Engineering \\ Division, King Abdullah University of Science and Technology, Thuwal 23955-6900, Kingdom of Saudi Arabia \\ ${ }^{2}$ High-Speed Fluids Imaging Laboratory, Physical Sciences and Engineering Division, King Abdullah \\ University of Science and Technology, Thuwal 23955-6900, Kingdom of Saudi Arabia
}

(Received 29 August 2015; accepted 28 September 2015; published online 26 October 2015)

\begin{abstract}
Flexibility can bring a new dimension to state-of-the-art electronics, such as rollable displays and integrated circuit systems being transformed into more powerful resources. Flexible electronics are typically hosted on polymeric substrates. Such substrates can be bent and rolled up, but cannot be independently fixed at the rigid perpendicular position necessary to realize rollable display-integrated gadgets and electronics. A reversibly bistable material can assume two stable states in a reversible way: flexibly rolled state and independently unbent state. Such materials are used in cycling and biking safety wristbands and a variety of ankle bracelets for orthopedic healthcare. They are often wrapped around an object with high impulsive force loading. Here, we study the effects of cumulative impulsive force loading on thinned $(25 \mu \mathrm{m})$ flexible silicon-based $n$-channel metal-oxide-semiconductor field-effect transistor devices housed on a reversibly bistable flexible platform. We found that the transistors have maintained their high performance level up to an accumulated $180 \mathrm{kN}$ of impact force loading. The gate dielectric layers have maintained their reliability, which is evidenced by the low leakage current densities. Also, we observed low variation in the effective electron mobility values, which manifests that the device channels have maintained their carrier transport properties. (C) 2015 AIP Publishing LLC. [http://dx.doi.org/10.1063/1.4934355]
\end{abstract}

Introducing the notion of transformational silicon electronics $^{1}$ has paved the way for integrating silicon-based, modern, high-performance electronic circuits that are mechanically flexible and optically semitransparent into various applications. While maintaining large-scale production and prototyping rapidity, this flexible and translucent scheme demonstrates the potential to transform conventionally stiff electronic devices into thin, foldable ones without compromising long-term performance and reliability. ${ }^{2-5}$ Recent research in flexible ${ }^{6-17}$ and stretchable ${ }^{18-29}$ electronics shows that flexibility has emerged as a central feature and game-changer, allowing not only for large-scale deployment of such devices in what is currently referred to as macroelectronics, ${ }^{30}$ but also opening the possibility of integration of flexible electronics on mechanically flexible and reversibly bistable platforms. ${ }^{31}$

Flexible display devices are arguably one of the most researched topics ${ }^{32-35}$ in the scholarly world, and most products on the market are based on organic light-emitting diode (OLED) technology and active thin-film organic devices. ${ }^{36-39}$ In recent years, it has become clear that the integration of flexible silicon- and inorganic materials-based devices into one electronic system shows promise to reshape the future of the electronics industry. ${ }^{40,41}$ Furthermore, Apple, Inc., has successfully filed a patent on "flexible electronic devices" 42 that presents a flexible and foldable smartphone design, including a variety of flexible components such as a display and a housing made from a deformable material. Samsung

\footnotetext{
${ }^{\text {a) }}$ Author to whom correspondence should be addressed. Electronic mail: MuhammadMustafa.Hussain@kaust.edu.sa
}

Electronics Co., Ltd., has also filed a patent application for a similar technology, a flexible frame that can act as a clothing clip, armband, and shoulder strap. ${ }^{43}$

In this study, we investigate the mechanical stability of flexible silicon-based metal-oxide-semiconductor field-effect transistors (MOSFETs) on a mechanically flexible and optically semitransparent porous silicon using a mechanically reversible bistable platform - a metallic bracelet (used in the fabrication of commercially available safety wristbands) that has two stable mechanical states: stretched and rolled. To study this bistable platform and understand how it achieves flexibility and bistability, we performed X-ray microanalysis and elemental mapping using an energy-dispersive X-ray (EDX) spectroscope equipped with a scanning electron microscope (SEM). Fig. 1(a) presents the EDX emission spectrum of a sample from the bistable structure, showing the set of peaks caused by stimulating the emission of characteristic X-rays. Fig. 1(b) shows the elemental composition of the specimen in terms of weight and atomic percentages. We observe that iron (Fe) and carbon (C) constitute the majority of the bistable structure, with approximately $86 \%$ and $5.5 \%$ weight percentages, respectively. We attribute the presence of oxygen (O) to the oxidation of the $\mathrm{Fe}-\mathrm{C}$ alloy during high-temperature processing. In addition, surface SEM images (inset in the upper right corner of Fig. 2(c)) verify the presence of nanopores distributed throughout the structure, allowing the $150 \mu$ m-thick metal alloy to internally absorb strain energy and thus achieve flexibility. The transistor gate stacks consist of 200-nm-thick layers of lightly doped (phosphorus (P), dopant carrier concentration $\left(\mathrm{N}_{\mathrm{a}}\right) \approx 10^{18} \mathrm{~cm}^{-3}$ ) polycrystalline silicon 

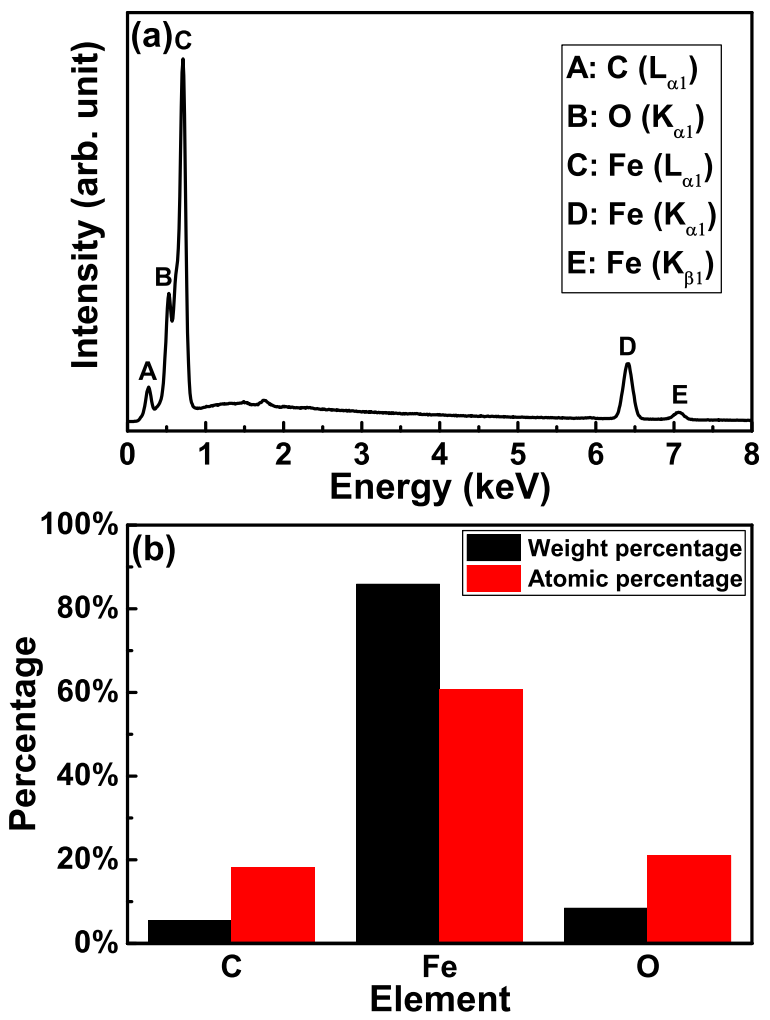

FIG. 1. (a) Energy-dispersive X-ray (EDX) spectrum of the bistable structure material and (b) a histogram demonstration of the chemical composition of the mechanically flexible and bistable material in terms of element weight and atomic percentages.

(poly-Si) acting as a gate electrode material and 20-nm-thick layers of $\mathrm{SiO}_{2}$ acting as gate dielectric layers, with measured relative permittivity of around 3.9. The detailed MOSFET fabrication and thinning processes can be found in our previous publications. ${ }^{4,5}$

To effectively conform to a reversibly bistable host material, a MOSFET device gate dielectric layer must stay intact with minimal gate-current leakage densities, and its channel must preserve its conductive properties for a given cumulative impact budget (CIB), which we define as the cumulative effect of impulsive forces up to a predefined number of impact cycles. The impulse of the net force (J) acting on a particle quantifies the effect of the net force $(\Sigma F)$ over the period of time it acts on an object. When the net force is expressed as a function of time, the impulse is defined as

$$
J=\int_{t_{1}}^{t_{2}} \Sigma F(t) d t=m\left(v_{2}-v_{1}\right)
$$

where $\Sigma F(t)$ is the time-variable net force, $m$ is the combined mass of the bistable platform and the transferred silicon fabric with MOSFET devices, $t_{1}$ and $t_{2}$ are times when the impulse starts and terminates, respectively, $v_{1}$ is the speed of the object at $t_{1}$, and $v_{2}$ is the speed of the object at $t_{2}$. Since the net force imparting an impulse to the silicon fabric varies in time, we define a time-averaged net force $\left((\Sigma \mathrm{F})_{\text {avg }}\right)$, which is a constant force that would impart an impulse to the silicon fabric during the same time interval that $\Sigma \mathrm{F}(\mathrm{t})$ acts on the fabric. By assuming the net force exerted in a given direction on the bistable platform by the hand is large
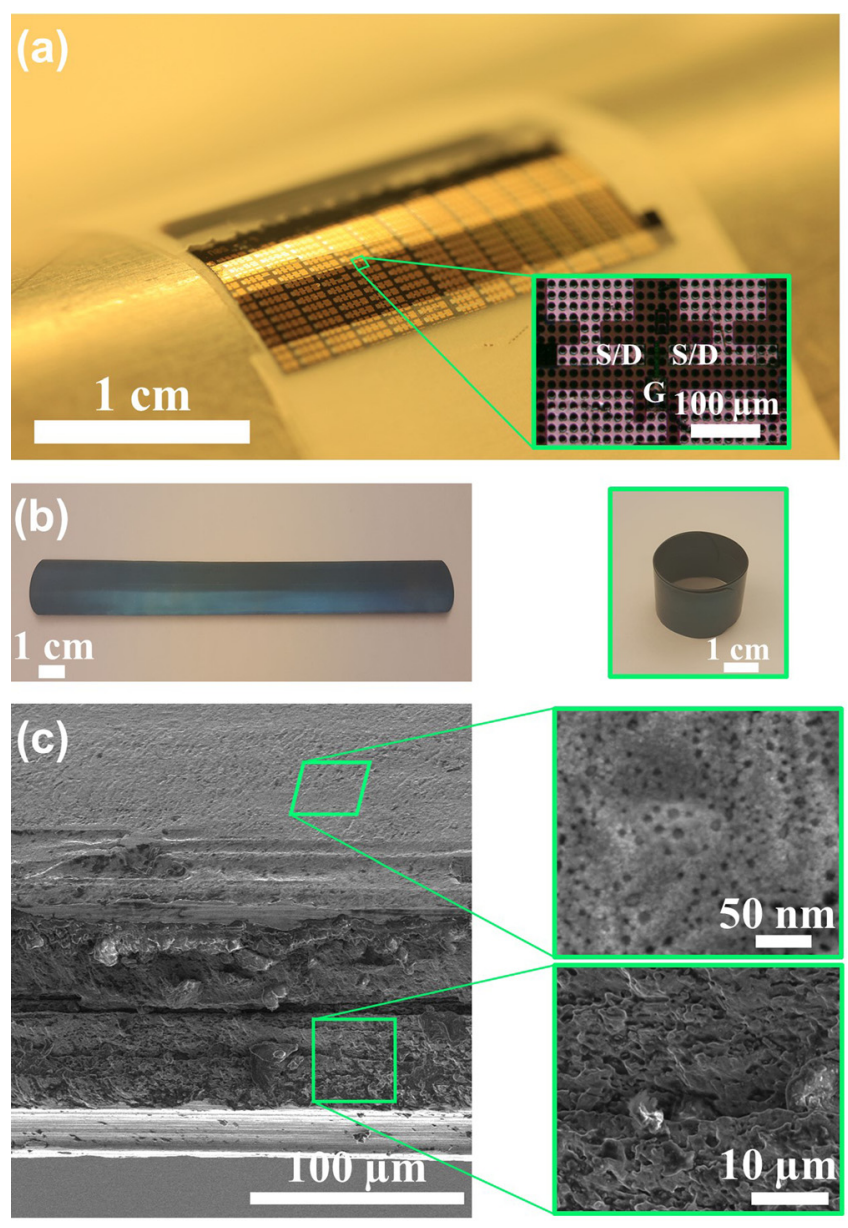

FIG. 2. (a) Digital photograph of transferred MOSFET silicon die onto metallic bistable structure. (b) Digital photographs of the metallic bistable structure. (c) Scanning electron microscope (SEM) cross-sectional and surface images of the bistable structure.

compared to air resistance, three force components contribute to $(\Sigma \mathrm{F})_{\text {avg }}$ : (i) the gravitational force $\left(\mathrm{F}_{\mathrm{g}}\right)$, (ii) the normal force exerted on the bistable platform by the steady hand $\left(\mathrm{F}_{\text {norm }}\right)$, and (iii) the force exerted by the moving hand on the bistable platform $\left(\mathrm{F}_{\mathrm{mov}}\right) .(\Sigma \mathrm{F})_{\text {avg }}$ is estimated as

$$
\begin{gathered}
(\Sigma F)_{a v g} \approx \frac{1}{\Delta t} \int_{t_{1}}^{t_{2}} \Sigma F(t) d t=\frac{J}{\Delta t}=\frac{m\left(v_{2}-v_{1}\right)}{\Delta t}, \\
\Delta t \approx \frac{\Delta y}{v_{\text {avg }}}=\frac{2 \Delta y}{v_{2}-v_{1}},
\end{gathered}
$$

where $v_{\text {avg }}$ is the average speed of the bistable platform during the impact, $\Delta t$ is the impact time, and $\Delta y$ is the impact distance. Fig. 3 demonstrates the variation in impulsive force magnitude and kinetic energy loss with impact speed (namely, $v_{1}$ ).

We attached our silicon fabric to the bistable platform using an acrylic-coated double-sided tape with a total thickness of $210 \mu \mathrm{m}$. The tape polyester carrier is about $12-\mu \mathrm{m}-$ thick. Considering the concept of mechanical neutral surfaces for materials with considerable differences in the elastic moduli, the neutral surface between a silicon sheet and a mechanically compliant material shifts toward the latter. ${ }^{44}$ Compared to the large elastic modulus for silicon, acrylic 


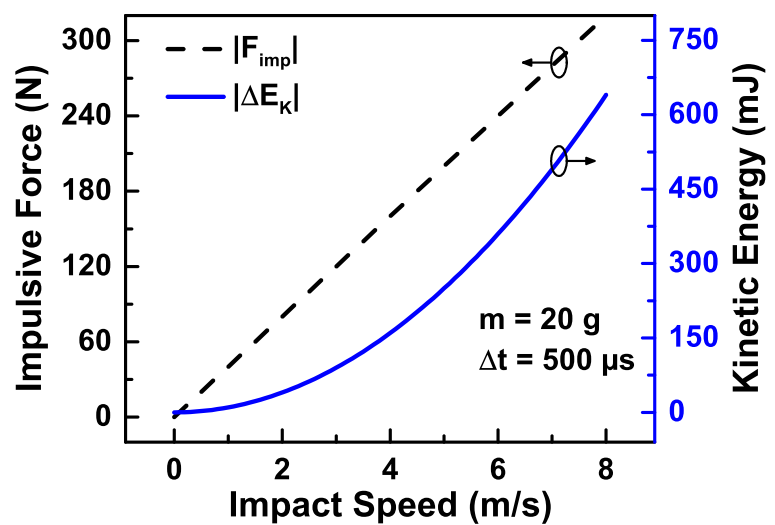

FIG. 3. Variation of impulsive force and loss in kinetic energy with impact speed.

and polyester have low elastic moduli of $Y_{\text {acrylic }}=3.2 \mathrm{GPa}$ and $Y_{\text {polyester }}=3.5 \mathrm{GPa}$. Hence, the neutral surface between the silicon fabric and the tape will shift accordingly, and the role of the double-sided tape extends beyond adhesion promotion as the low moduli acrylic and polyester layers reduced the total applied strain on the silicon fabric, $\epsilon$, which we can determine as

$$
\epsilon=\underbrace{\frac{\chi \eta^{2}+2 \eta+1}{(1+\chi \eta)(1+\eta)}}_{\phi} \underbrace{\frac{t_{\text {Si }}+t_{\text {tape }}}{2 R}}_{\epsilon_{\max }},
$$

where $t_{S i}$ and $t_{\text {tape }}$ are the silicon fabric and tape thicknesses, respectively, $R$ is the curvature radius, $\eta=t_{S i} / t_{\text {tape }}$, and $\chi=Y_{S i} / Y_{\text {tape }}$. If we take $Y_{\text {tape }}=Y_{\text {polyester }}$, we can safely obtain a stress reduction factor $(1 / \phi)$ of about 4.05 .

We used the linear extrapolation method ${ }^{45}$ to extract the threshold voltage $\left(\mathrm{V}_{\mathrm{TH}}\right)$ values for our devices. The transconductance $\left(\mathrm{g}_{\mathrm{m}}\right)$ of a transistor is defined as a measure of the variation in the drain-to-source current $\left(\mathrm{I}_{\mathrm{DS}}\right)$ with respect to $\mathrm{V}_{\mathrm{GS}}$ at a constant drain-to-source voltage $\left(\mathrm{V}_{\mathrm{DS}}\right)$

$$
g_{m}=\left.\frac{\partial I_{D S}}{\partial V_{G S}}\right|_{V_{D S}=\text { const }} .
$$

The transresistance $\left(g_{d}\right)$ of a transistor is defined as a measure of the variation in $\mathrm{I}_{\mathrm{DS}}$ with respect to $\mathrm{V}_{\mathrm{DS}}$ at a constant $\mathrm{V}_{\mathrm{GS}}$

$$
g_{d}=\left.\frac{\partial I_{D S}}{\partial V_{D S}}\right|_{V_{G S}=\text { const } .} .
$$

The effective channel mobility $\left(\mu_{\text {eff }}\right)$ refers to the spatial average of the mobility profile in the inversion layer of a MOSFET channel. Frequency and time response performance of a transistor are directly affected by the charge carrier mobility because the carrier velocity, at a low electric field, is directly proportional to the mobility. Therefore, a higher mobility material leads to faster time response due to charge carriers - in this case, taking less time to travel through the device. In addition, capacitors are more rapidly charged with higher mobility devices, resulting in a higher frequency response. At low $\mathrm{V}_{\mathrm{DS}}$ values $(100 \mathrm{mV}$ in our case), the channel charge profile is, to a greater extent, uniform, resulting in $d Q / d x=0$, where $Q$ is the channel charge density (often expressed in $\mathrm{C} / \mathrm{cm}^{2}$ ) and is approximately equal to $C_{O X}\left(V_{G S}-V_{T H}\right), C_{\mathrm{OX}}$ is the gate dielectric oxide capacitance per unit area, and $x$ is a parameter that specifies the distance into the channel. Therefore, we estimated $\mu_{\text {eff }}$ values using the equation ${ }^{46}$

$$
\mu_{e f f}=\frac{g_{d} L}{W C_{O X}\left(V_{G S}-V_{T H}\right)} .
$$

The reversibly bistable platform ( $m=20 \mathrm{~g}$; metal density $(\rho)=10.09 \mathrm{~g} / \mathrm{cm}^{3}$; ultimate tensile strength $\left(\sigma_{t s}\right)$ in the
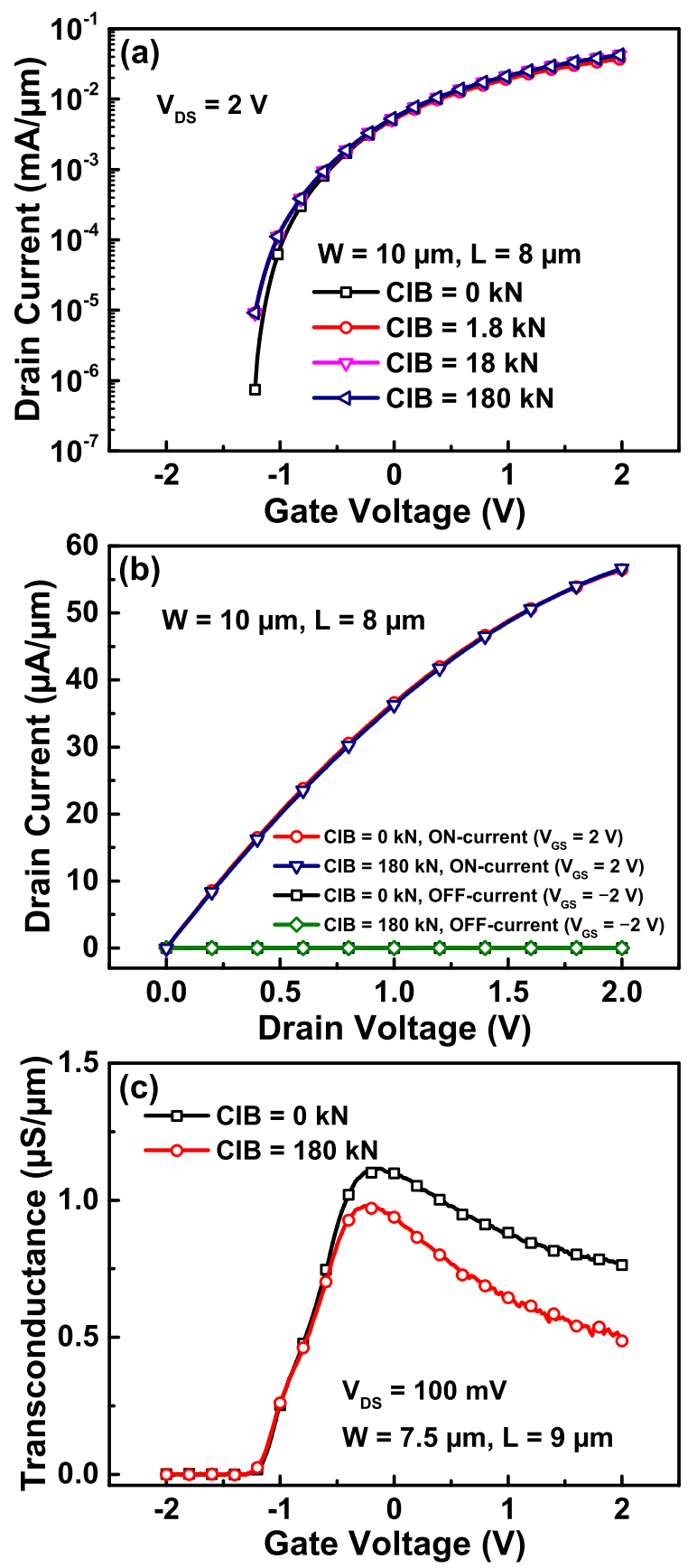

FIG. 4. Normalized saturation (a) transfer and (b) output current-voltage (I-V) characteristics of a representative MOSFET device and (c) transconductance variation in another representative MOSFET device as a result of impulsive force loading. 
range of 345-724 MPa; and modulus of elasticity in tension $\left.\left(Y_{F e-C}\right) \approx 170 \mathrm{GPa}\right)^{47,48}$ was repeatedly accelerated toward a human hand, with an impact speed $v_{1}$ of approximately $4.45 \mathrm{~m} / \mathrm{s}$ and an impact distance $\Delta y$ of about $2.25 \mathrm{~mm}$, resulting in an impact time $\Delta t$ of roughly $500 \mathrm{~ms}$ and an impulsive force $(\Sigma F)_{\text {avg }}$ with a magnitude of almost $180 \mathrm{~N}$ during each impact cycle. We observed the accumulative effect of applying such impulsive forces and reported the results in relation to CIB. Figs. 4(a) and 4(b) show the transfer and output characteristic curves, respectively, of a representative MOSFET device, comparing its behavior before and after impulsive force loading. We observed negligible variation in device performance as the on-state current $\left(\mathrm{I}_{\mathrm{ON}}\right)$ varied between $37.41 \mu \mathrm{A} / \mu \mathrm{m}$ and $42.70 \mu \mathrm{A} / \mu \mathrm{m} . \mathrm{g}_{\mathrm{m}}$ measurements of another representative MOSFET device before and after accumulating a CIB of $180 \mathrm{kN}$ are depicted in Fig. 4(c). We observed that the maximum $\mathrm{g}_{\mathrm{m}}$ value for this transistor drops from $8.92 \mu \mathrm{S} / \mu \mathrm{m}$ to $7.83 \mu \mathrm{S} / \mu \mathrm{m}$ after accumulating a CIB of $180 \mathrm{kN}$. Fig. 5(a) shows the average device performance, comparing average maximum $\mathrm{g}_{\mathrm{m}}$ values $\left(\mathrm{g}_{\mathrm{m}}\right.$, avg $)$ with average maximum $\mu_{\text {eff }}$ values $\left(\mu_{\text {eff, avg }}\right.$ ) after each impact cycle while operating in the linear mode of operation. Fig. 5(b) compares the average $\mathrm{V}_{\mathrm{TH}}$ magnitude values $\left(\left|\mathrm{V}_{\mathrm{TH}, \text { avg }}\right|\right)$ with average on-to-off current ratio values after each impact cycle. The difference in maximum $\mathrm{g}_{\mathrm{m}}$, avg and maximum

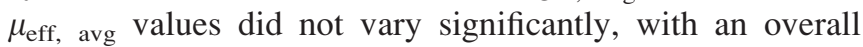
drop of $6.08 \%$ and $5.40 \%$, respectively. As can be seen in Fig. 5(b), the fluctuation in $\left|\mathrm{V}_{\mathrm{TH}, \text { avg }}\right|$ value is within $10 \%$.

Finally, Fig. 5(c) shows the variation in subthreshold swing (SS) and drain-induced barrier lowering (DIBL) values as a result of applying impulsive forces. Increases in SS values are attributed to increased defect densities at the interfaces between the oxide and channel layers after impulsive force loading. This effect appears perceptibly in two devices that have lower channel width-to-length ratios $(0.83$ and 0.75 compared to 1.25 ), resulting in lower $n$-channel conduction parameter $\left(\mathrm{K}_{\mathrm{n}}\right) . \mathrm{K}_{\mathrm{n}}$ is directly proportional to $\mathrm{C}_{\mathrm{OX}}$, whereas $\mathrm{SS}$ is directly proportional to $\mathrm{C}_{\mathrm{D}} / \mathrm{C}_{\mathrm{OX}}{ }^{49}$

In summary, we have introduced a host material for flexible electronics, a platform that is mechanically flexible and reversibly bistable. We have also introduced a performance metric, namely, the cumulative impact budget, which takes into account the impact force imparting an impulse on the silicon fabric during the mechanical deformation of the substrate. Moreover, we have shown that the MOSFET devices on the $25-\mu$ m-thick silicon fabric have generally maintained their high performance level after accumulating impulsive force budgets of $180 \mathrm{kN}$. The use of soft materials as adhesion layers helped in mitigating the applied stress during each impact cycle. Minimal variations in $\mathrm{I}_{\mathrm{ON}}$ and average maximum $g_{m}$ values indicate that the devices have maintained their operational stability. Most importantly, average maximum $\mu_{\text {eff }}$ values have not deteriorated significantly, suggesting that the MOSFET channels have preserved their conductive properties after impulsive force loading. The only significant performance degradation is the increase in subthreshold swing values. We conjecture that successive application of impulsive forces has caused more trapped charges at the oxidechannel interfaces, resulting in reductions in $\mathrm{C}_{\mathrm{OX}}$ values and
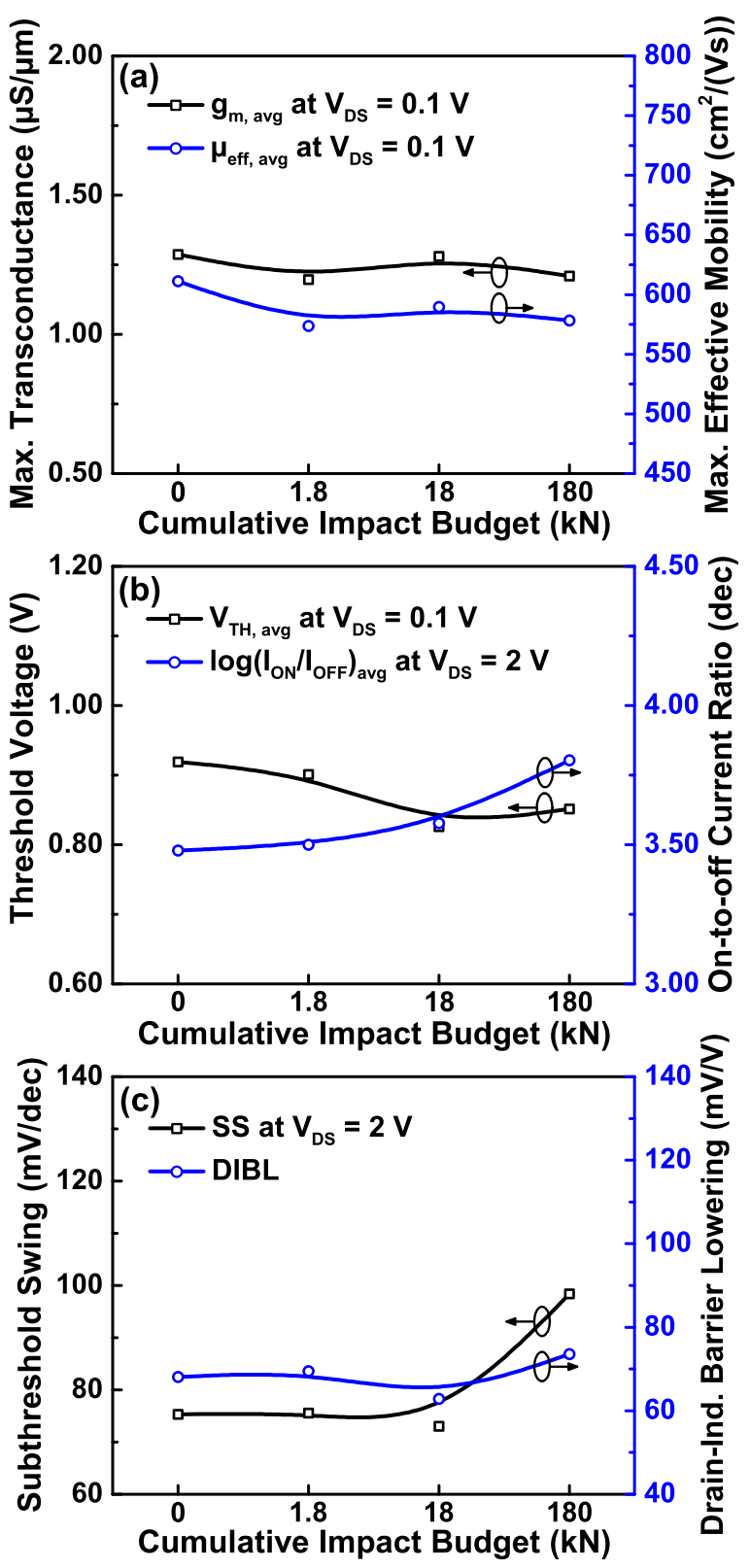

FIG. 5. (a) Average maximum transconductance and effective mobility values, (b) average threshold voltage and on-to-off current ratio values, and (c) subthreshold swing and drain-induced barrier lowering values variation as a result of impulsive force loading.

therefore decreasing $\mathrm{K}_{\mathrm{n}}$ and increasing the ratio of the depletion capacitance to the oxide layer capacitance $\left(\mathrm{C}_{\mathrm{D}} / \mathrm{C}_{\mathrm{OX}}\right)$.

Research reported in this publication was supported by the KAUST Office of Competitive Research Grant 1: CRG1-2012-HUS-008.

${ }^{1}$ J. P. Rojas, G. A. Torres Sevilla, M. T. Ghoneim, S. B. Inayat, S. M. Ahmed, A. M. Hussain, and M. M. Hussain, ACS Nano 8, 1468 (2014).

${ }^{2}$ J. P. Rojas, G. Torres Sevilla, and M. M. Hussain, Appl. Phys. Lett. 102, 064102 (2013).

${ }^{3}$ A. Diab, G. A. Torres Sevilla, M. T. Ghoneim, and M. M. Hussain, Appl. Phys. Lett. 105, 133509 (2014).

${ }^{4}$ J. P. Rojas, G. A. T. Sevilla, and M. M. Hussain, Sci. Rep. 3, 2609 (2013).

${ }^{5}$ J. P. Rojas, G. A. Torres Sevilla, N. Alfaraj, M. T. Ghoneim, A. T. Kutbee, A. Sridharan, and M. M. Hussain, ACS Nano 9, 5255 (2015).

${ }^{6}$ G.-T. Hwang, D. Im, S. E. Lee, J. Lee, M. Koo, S. Y. Park, S. Kim, K. Yang, S. J. Kim, K. Lee, and K. J. Lee, ACS Nano 7, 4545 (2013). 
${ }^{7}$ H. S. Lee, J. Chung, G.-T. Hwang, C. K. Jeong, Y. Jung, J.-H. Kwak, H. Kang, M. Byun, W. D. Kim, S. Hur et al., Adv. Funct. Mater. 24, 6914 (2014).

${ }^{8}$ H. Wu, D. Kong, Z. Ruan, P.-C. Hsu, S. Wang, Z. Yu, T. J. Carney, L. Hu, S. Fan, and Y. Cui, Nat. Nanotechnol. 8, 421 (2013).

${ }^{9}$ G. A. T. Sevilla, S. B. Inayat, J. P. Rojas, A. M. Hussain, and M. M. Hussain, Small 9, 3916 (2013).

${ }^{10}$ G. A. T. Sevilla, J. P. Rojas, H. M. Fahad, A. M. Hussain, R. Ghanem, C. E. Smith, and M. M. Hussain, Adv. Mater. 26, 2794 (2014).

${ }^{11}$ M. T. Ghoneim, A. Kutbee, F. Ghodsi Nasseri, G. Bersuker, and M. M. Hussain, Appl. Phys. Lett. 104, 234104 (2014).

${ }^{12}$ M. T. Ghoneim, M. A. Zidan, M. Y. Alnassar, A. N. Hanna, J. Kosel, K. N. Salama, and M. M. Hussain, Adv. Electron. Mater. 1(6) (2015).

${ }^{13}$ M. T. Ghoneim and M. M. Hussain, Appl. Phys. Lett. 107, 052904 (2015).

${ }^{14}$ M. T. Ghoneim and M. M. Hussain, Electronics 4, 424-479 (2015).

${ }^{15}$ J. M. Nassar, A. M. Hussain, J. P. Rojas, and M. M. Hussain, Phys. Status Solidi RRL 8, 794 (2014).

${ }^{16}$ M. T. Ghoneim, N. Alfaraj, G. A. Torres Sevilla, H. M. Fahad, and M. M. Hussain, in 73rd Annual Device Research Conference (DRC), Columbus, OH (2015), pp. 95-96.

${ }^{17}$ M. T. Ghoneim, N. Alfaraj, G. A. Torres Sevilla, A. Kutbee, and M. M. Hussain, in 15th International Conference on Nanotechnology, Rome, Italy, 2015.

${ }^{18}$ J. A. Rogers, T. Someya, and Y. Huang, Science 327, 1603 (2010).

${ }^{19}$ J. Wu, Z. J. Liu, J. Song, Y. Huang, K.-C. Hwang, Y. W. Zhang, and J. A. Rogers, Appl. Phys. Lett. 99, 061911 (2011).

${ }^{20}$ T. Sekitani and T. Someya, Adv. Mater. 22, 2228 (2010).

${ }^{21}$ J. Song, Y. Huang, J. Xiao, S. Wang, K. C. Hwang, H. C. Ko, D.-H. Kim, M. P. Stoykovich, and J. A. Rogers, J. Appl. Phys. 105, 123516 (2009).

${ }^{22}$ H. Fu, S. Xu, R. Xu, J. Jiang, Y. Zhang, J. A. Rogers, and Y. Huang, Appl. Phys. Lett. 106, 091902 (2015).

${ }^{23}$ C. K. Jeong, J. Lee, S. Han, J. Ryu, G.-T. Hwang, D. Y. Park, J. H. Park, S. S. Lee, M. Byun, S. H. Ko, and K. J. Lee, Adv. Mater. 27, 2866 (2015).

${ }^{24}$ J. S. Hwang, J. Y. Cho, S. Y. Park, Y. J. Yoo, P. S. Yoo, B. W. Lee, and Y. P. Lee, Appl. Phys. Lett. 106, 062902 (2015).

${ }^{25}$ R. Tang, H. Huang, H. Tu, H. Liang, M. Liang, Z. Song, Y. Xu, H. Jiang, and H. Yu, Appl. Phys. Lett. 104, 083501 (2014).

${ }^{26}$ Z. Song, X. Wang, C. Lv, Y. An, M. Liang, T. Ma, D. He, Y.-J. Zheng, S.Q. Huang, H. Yu et al., Sci. Rep. 5, 10988 (2013).

${ }^{27}$ S. P. Lacour, J. Jones, S. Wagner, T. Li, and Z. Suo, Proc. IEEE 93, 1459 (2005).

${ }^{28}$ J. P. Rojas, A. Arevalo, I. G. Foulds, and M. M. Hussain, Appl. Phys. Lett. 105, 154101 (2014).
${ }^{29}$ A. M. Hussain, E. B. Lizardo, G. A. Torres Sevilla, J. M. Nassar, and M. M. Hussain, Adv. Healthcare Mater. 4, 665 (2015).

${ }^{30}$ R. Reuss, B. Chalamala, A. Moussessian, M. G. Kane, A. Kumar, D. Zhang, J. Rogers, M. Hatalis, D. Temple, G. Moddel, B. Eliasson, M. Estes, J. Kunze, E. Handy, E. Harmon, D. Salzman, J. Woodall, M. Alam, J. Y. Murthy, S. Jacobsen, M. Olivier, D. Markus, P. Campbell, and E. Snow, Proc. IEEE 93, 1239 (2005).

${ }^{31}$ N. Alfaraj, M.S. thesis, King Abdullah University of Science and Technology, 2015.

${ }^{32}$ S.-I. Park, Y. Xiong, R.-H. Kim, P. Elvikis, M. Meitl, D.-H. Kim, J. Wu, J. Yoon, C.-J. Yu, Z. Liu, Y. Huang, K.-c. Hwang, P. Ferreira, X. Li, K. Choquette, and J. A. Rogers, Science 325, 977 (2009).

${ }^{33}$ L. Zhou, A. Wanga, S.-C. Wu, J. Sun, S. Park, and T. N. Jackson, Appl. Phys. Lett. 88, 083502 (2006).

${ }^{34}$ P. Mach, S. J. Rodriguez, R. Nortrup, P. Wiltzius, and J. A. Rogers, Appl. Phys. Lett. 78, 3592 (2001).

${ }^{35}$ X. Hu, P. Krull, B. de Graff, K. Dowling, J. A. Rogers, and W. J. Arora, Adv. Mater. 23, 2933 (2011).

${ }^{36}$ B. Geffroy, P. Le Roy, and C. Prat, Polym. Int. 55, 572 (2006).

${ }^{37}$ S. R. Forrest, Nature 428, 911 (2004).

${ }^{38}$ J. He, R. Nuzzo, and J. Rogers, Proc. IEEE 103, 619 (2015).

${ }^{39}$ J. Sun, B. Zhang, and H. E. Katz, Adv. Funct. Mater. 21, 29 (2011).

${ }^{40}$ T.-i. Kim, S. Hyun Lee, Y. Li, Y. Shi, G. Shin, S. Dan Lee, Y. Huang, J. A. Rogers, and J. Su Yu, Appl. Phys. Lett. 104, 051901 (2014).

${ }^{41}$ H. Jang, W. Lee, S. M. Won, S. Y. Ryu, D. Lee, J. B. Koo, S.-D. Ahn, C.W. Yang, M.-H. Jo, J. H. Cho, J. A. Rogers, and J.-H. Ahn, Nano Lett. 13, 5600 (2013).

${ }^{42}$ J. Franklin, S. Myers, B. Rappoport, S. Lynch, J. Ternus, and J. Wodrich, "Flexible electronic devices," U.S. patent 8,929,085 (2015).

${ }^{43}$ I. Kim, "Flexible electronic device," U.S. patent application 14/272,715 (2015).

${ }^{44}$ Z. Suo, E. Y. Ma, H. Gleskova, and S. Wagner, Appl. Phys. Lett. 74, 1177 (1999).

${ }^{45}$ D. K. Schroder, Semiconductor Material and Device Characterization (John Wiley \& Sons, New York, 2006), pp. 223-224.

${ }^{46}$ D. K. Schroder, Semiconductor Material and Device Characterization (John Wiley \& Sons, New York, 2006), pp. 489-490.

${ }^{47}$ J. R. Davis, ASM Specialty Handbook: Cast Irons (ASM International, 1996), p. 101.

${ }^{48}$ J. F. Shackelford and W. Alexander, CRC Materials Science and Engineering Handbook (CRC Press, 2000), p. 539.

${ }^{49}$ S. M. Sze and K. K. Ng, Physics of Semiconductor Devices (John Wiley \& Sons, New York, 2006), p. 315. 